\title{
CRESCIMENTO DA PRODUTIVIDADE NO SETOR DE SERVIÇOS E DA INDÚSTRIA NO BRASIL: DINÂMICA E HETEROGENEIDADE
}

\author{
Paulo de Andrade Jacinto * \\ Eduardo Pontual Ribeiro ${ }^{\dagger}$
}

\begin{abstract}
Resumo
O presente estudo analisa a evolução da produtividade do setor de serviços focando na relação entre estrutura e crescimento. A partir das informações das Contas Nacionais e da Pesquisa Anual de Serviços e do uso de decomposições para explorar a dinâmica da produtividade, os resultados mostram que o setor de serviços é um setor com alta produtividade. No período de 2002 a 2009, a evolução da produtividade desse setor foi positiva com um desempenho superior ao da indústria de transformação desde 1996. Não há evidências favoráveis para a existência da doença de custos no Brasil e tanto na indústria como nos serviços, não se verificou uma associação positiva entre mudanças na estrutura e ganhos de produtividade, o chamado bônus estrutural.
\end{abstract}

Palavras-chave: Serviços; Produtividade; Doença de custos.

\begin{abstract}
This work aimed to evaluate the evolution of the service sector productivity focusing on the relationship between structure and growth. Information from the National Accounts and from the Annual Services Survey (PAS in Portuguese) was used, as well as decompositions to investigate productivity dynamics. The results show that the service sector is a sector with high productivity. Productivity growth in services was positive from 2002 to 2009 and since 1996 its performance was superior to manufacturing. There is no evidence supporting the existence of the cost disease in Brazil and neither in industry nor in services a positive relation between changes in the structure and productivity gains, known as structural bonus was found.
\end{abstract}

Keywords: Services; Productivity; Cost disease.

JEL classification: E24, L8, L80

DOI: http ://dx.doi .org/10.1590/1413-8050/ea119450

\footnotetext{
* Pontifícia Universidade do Rio Grande do Sul. E-mail: paulo.jacinto@pucrs.br

† Universidade Federal do Rio de Janeiro. E-mail: eribeiro@ie.ufrj.br
} 


\section{Introdução}

Nos últimos anos, os estudos sobre a evolução da produtividade vêm cada vez mais ganhando espaço no debate econômico no Brasil. Isso pode ser visto pelo número de estudos como os de Bonelli \& Fonseca (1998), Rocha (2007), Gomes et al. (2003), Rocha (1999), Barbosa Filho et al. (2010) entre outros. Estudar o padrão de evolução da produtividade se justifica pela necessidade de entender e acompanhar a competitividade de um país seja para manter um espaço no cenário internacional ou sustentar o crescimento econômico.

Pinheiro (2012) argumenta que setores intensivos em trabalho como o comércio lideraram a expansão do PIB recente. A mudança estrutural da economia brasileira para o setor terciário pode levar a uma desaceleração do crescimento agregado da produtividade por um efeito composição, dada pela menor produtividade nesses últimos setores, vis a vis a produtividade da Indústria (e Agricultura). Nessa mesma direção Bonelli \& Fonseca (1998) mostra que o movimento para o setor terciário reduziu o crescimento no país entre 1990 e 2000, ao contrário das décadas anteriores, onde o crescimento da indústria acima da média da economia fez com que as mudanças de estrutura fossem pró-crescimento.

Essa preocupação não se restringe ao Brasil. Na literatura econômica internacional, Baumol (1967) e Baumol et al. (1985) trazem estudos seminais sobre a relação da produtividade do setor de serviços e de outros setores. À medida que o setor de serviços ampliasse a sua participação no PIB e, consequentemente, no trabalho, uma economia caminharia para a estagnação devido ao pobre desempenho produtivo desse setor, a chamada doença de custos dos serviços. Rodrik (2011) e Rodrik (2014) mantém o debate, em um contexto de países em desenvolvimento e para um período mais recente. Busso et al. (2013) é ainda mais enfática, ao afirmar que o problema do fraco desempenho da produtividade na América Latina desde os anos 1980 até o início dos anos 2000 deve-se ao desempenho do setor de serviços.

Já De La Torre et al. (2013) afirmam que em um ambiente de dinâmica de commodities mais fraca, puxado pelas dificuldades econômicas da Europa e pela desaceleração da China, uma estratégia de crescimento para a América Latina passa pelo fortalecimento do setor de serviços e estes têm contribuído positivamente para o crescimento econômico na América Latina, de modo geral, desde a crise de 2008. A questão passa por reconhecer a heterogeneidade dos serviços em termos de conteúdo tecnológico e sensibilidade à renda domiciliar e concluir que os serviços podem contribuir positivamente para o desenvolvimento, como estimam Timmer \& de Vries (2009) para países da América Latina e Ásia.

Essa é uma crítica comum à análise inicial de Baumol (1967), como em Silva (2006), citando uma referência no Brasil. Há divisões de serviços nas quais a inovação é permanente, como serviços de informação e software e outros, nos quais a inovação é menor, mas com grande impacto no emprego e geração de renda devido ao tamanho, como apontam Pereira et al. (2013). Dessa forma, os serviços possuem potencial de crescimento da produtividade e de relevância econômica.

É nesse contexto que se insere o presente estudo, ao estudar a evolução da produtividade do setor de serviços, contrastando-a com outros setores da economia, com destaque para a indústria. A análise envolve o olhar detalhado nos serviços a partir da análise das Contas Nacionais e da Pesquisa Anual de 
Serviços (PAS) do IBGE, em um horizonte longo, desde 1996 a 2009, ainda não explorado na literatura ${ }^{1}$.

A mensuração propriamente dita da produtividade nos subsetores envolve questões metodológicas relevantes como mudanças de classificação e construção de deflatores. A análise emprega decomposições do crescimento da produtividade agregada, que permitem lançar luz sobre a relação entre estrutura e dinâmica, como destacam Ribeiro (2005) e Rocha (2007). As decomposições tentam isolar a contribuição da estrutura produtiva (distribuição relativa do emprego ou produto nos setores) para o crescimento da produtividade agregada. As decomposições podem ser de duas formas: uma em que o efeito estrutural é isolado, construindo um crescimento de produtividade contra-factual (hipotético) sem mudanças na estrutura, supondo ortogonalidade entre estrutura e crescimento da produtividade. Outra decomposição, com menos hipóteses restritivas, verifica a associação entre dinâmica estrutural e crescimento da produtividade focando a possibilidade de bônus estrutural, ou seja, a situação em que a produtividade cresce em setores que ganham relevância na estrutura produtiva. Ainda há uma terceira decomposição, em que se avalia o grau de associação entre estrutura e produtividade a cada ano.

Adiantando os resultados, é possível verificar que o setor de serviços, ao contrário do senso comum, é um setor produtivo. Verificou-se também que a evolução da produtividade desse setor foi positiva no período de 2002 a 2009, contrastando com queda na indústria. Não encontramos evidências favoráveis para a existência da doença de custos no Brasil no período de 2002-2009, uma vez que a produtividade serviços cresceu mais que indústria, particularmente dos serviços prestados às empresas, mesmo com o aumento da importância dos serviços no consumo intermediário da indústria. A partir de informações da PAS verificou-se ainda que as divisões que compõe os serviços são heterogêneas e que os serviços prestados às empresas tiveram aumento de produtividade, descartando, mais uma vez, a possibilidade de explicação do desempenho pífio da produtividade da indústria de transformação pela mudança estrutural da economia para os serviços. Por fim, o padrão de crescimento da produtividade dos serviços apresentou similaridades e diferenças em relação à indústria: enquanto que em ambos a dinâmica da produtividade é, em geral, explicada pelo comportamento intra-setorial, e não se verificou o bônus estrutural, por outro lado, nos serviços encontramos um efeito positivo de realocação de mão de obra para setores mais produtivos para a dinâmica da produtividade, ao contrário da indústria.

Além dessa introdução, o trabalho está dividido em quatro seções. A próxima traz uma resenha sobre a literatura nacional de produtividade na indústria e nos serviços. A seção seguinte descreve a metodologia de mensuração da produtividade e discute os métodos de decomposição empregados para extrair informação a partir da evolução da produtividade, seguida pela seção dos resultados empíricos, e a última apresenta as considerações finais.

\footnotetext{
${ }^{1}$ Apesar de a evolução da produtividade depender da inovação, não iremos explorar a PINTEC pois a mesma cobre apenas alguns subsetores específicos do setor de serviços. Este certamente é outro trabalho, complementar a este, cuja referência básica é Silva (2006).
} 


\section{Produtividade na indústria e serviços no Brasil: uma síntese da literatura}

Em geral, os estudos mais recentes sobre a produtividade na indústria seguem três direções e mostram como o debate evoluiu. Na primeira direção, a preocupação estava em verificar diferenças de metodologias e informações empregadas na mensuração da produtividade (Salm et al. 1997, Feijó \& Carvalho 1999). Na segunda direção, os estudos deram ênfase na identificação dos determinantes que contribuíram para o crescimento da produtividade. Nas análises, ficou evidente o papel desempenhado pela abertura comercial no início dos anos 90 (Ferreira \& Rossi 2003, Schor 2006, Rocha 2007).

Por fim, a produtividade da indústria passou a ser associada ao desempenho do setor de serviços em virtude da crescente participação desse setor no PIB.

O trabalho mais influente que associa a produtividade da indústria e da economia como um todo ao desempenho dos serviços foi apresentado por Baumol (1967). A teoria desenvolvida em sua análise ficou conhecida como a doença de custos. A principal inquietação desse autor estava no fato de que à medida que o setor de serviços ampliasse a sua participação no PIB e, consequentemente, no trabalho, a economia caminharia para a estagnação devido ao pobre desempenho produtivo desse setor.

$\mathrm{Na}$ literatura nacional, o impacto do crescimento do setor de serviços na produtividade da economia, tentando inferir sobre a doença de custos no Brasil, foi avaliado inicialmente por Melo et al. (1998). Os resultados encontrados mostraram que não havia evidências favoráveis à existência da doença de custos para os anos 80 e 90, baseado em dados agregados apenas. Kon \& Kume (2004) também discorre sobre o tema.

A existência da doença de custos também foi explorada por Oliveira (2011), que realizou um estudo comparativo da contribuição dos serviços para o crescimento no Brasil, nos EUA e na Zona do Euro, usando informações de Contas Nacionais. A autora argumenta que no Brasil os serviços auxiliaram o crescimento da produtividade agregada após 1994 e descartou a possibilidade de doença de custos na indústria devido aos serviços por seu desempenho até meados da década de 2000, relativamente ao desempenho em outros países.

São raros os estudos no Brasil sobre a produtividade do setor de serviços que não a relaciona com a indústria ${ }^{2}$. Silva (2006) utiliza a Pesquisa Anual de Serviços (PAS) para estudar a dinâmica da produtividade nos serviços empregando microdados, com ênfase em decomposições, como este artigo, mas restringe a análise a apenas onze divisões representantes de quatro grupos relevantes dos serviços (telecomunicações, informação, serviços prestados à empresa e os culturais).

Em síntese, os estudos sobre produtividade no país deram ênfase à indústria, com poucos estudos no setor de serviços e na sua relação com a indústria como relatado acima. Explorando apenas dados agregados, esses estudos sugerem que a produtividade do setor de serviços não poderia ser uma explicação para a estagnação da produtividade na indústria e na economia no Brasil.

Com intuito de avançar com a literatura, o presente estudo apresenta uma análise para o setor de serviços (de modo isolado do comércio) para o período

\footnotetext{
${ }^{2}$ Rocha (1999) trata da participação dos serviços no consumo intermediário da indústria, mas não diretamente da produtividade, para os anos de 1985, 1990 e 1992.
} 
pós Plano Real, utilizando informações ainda pouco exploradas da PAS do IBGE e desagregando informações das Contas Nacionais. Ou seja, o estudo avança em relação aos anteriores na medida em que (i) utiliza informações mais desagregadas para revelar a heterogeneidade e a associação com a dinâmica dentro desse setor, (ii) faz uso de decomposições que permitem entender o diferencial na trajetória da produtividade entre os setores de serviços e indústria de forma comparativa. Para realizar essa análise, dois desafios precisam ser contornados e que também avançam em relação à literatura acima citada. O primeiro é o uso de deflatores específicos aos subsetores da PAS calculados a partir das Contas Nacionais. O segundo está relacionado aos efeitos da mudança de classificação setorial em 2007 da CNAE 1.0 para CNAE 2.0 sobre a evolução de medidas de produção e emprego, para o qual propomos um procedimento novo, encontrado no Anexo 1. Estes temas são tratados na próxima seção.

\section{Mensuração da produtividade e decomposições empregadas}

As medidas de produtividade baseiam-se em duas fontes de dados. Primeiro, as contas nacionais do IBGE, para permitir uma comparação entre todos os setores da economia. Todavia como a agregação dos serviços é bastante restritiva (apenas Transporte, Comunicações, Instituições financeiras, Serviços prestados às famílias, Serviços prestados às empresas, Aluguel de imóveis, além de Administração pública e Serviços privados não mercantis), faz-se mister utilizar outra fonte de dados. Além disso, entre os serviços está a Administração Pública e Serviços privados não mercantis, que têm uma forma de mensuração de produção peculiar em relação aos outros setores. Assim, em um segundo momento, será utilizada a Pesquisa Anual de Serviços - PAS, ainda não empregada para este tipo de estudo.

A PAS cobre vários subsetores que podem ser agrupados em Serviços prestados às famílias; Serviços de informação; Serviços prestados às empresas; Transportes, Serviços auxiliares aos transportes e correio; Atividades imobiliárias; Serviços de manutenção e reparação; Outras atividades de serviços, inclusive financeiros. (em detalhes, as CNAEs 50, 51, 55, 60 a 64, 67, 70 a 74, 80 e 90 na classificação 1.0). O uso da PAS para análise exige a superação de dois problemas metodológicos: a compatibilização setorial entre as classificações CNAE 1.0 (de 2002 a 2007) e 2.0 (para 2007 a 2009); e o cálculo de deflatores para a produtividade.

Em relação a este primeiro ponto, o emprego da PAS para análise da evolução de produtividade exige um tratamento da mudança de classificação setorial de CNAE 1.0 para CNAE 2.0 em 2008. Mesmo com o uso de dicionários "de-para" do IBGE (Concla), a mudança do número de firmas classificadas em cada setor com a mudança da classificação levaria a mudanças na evolução dos índices setoriais de produtividade espúrias, pois seriam determinadas apenas pelo efeito composição da mudança do número de firmas sob certa classificação setorial. Para evitar esse problema, propomos uma metodologia nova que explora a existência de um ano (2007) com ambas as classificações setoriais para a construção de índices de emprego, produção e produtividade que podem tomar a base de classificação de qualquer classificação setorial, em analogia a índices das contas nacionais a preços de fim de período ou de início de período de análise. Os detalhes da metodologia aparecem no Anexo deste 
trabalho.

A produtividade pode ser mensurada de diferentes formas, diferenciadas pela necessidade de informações e pelo auxílio de alguma estrutura analítica. Inicialmente, há o valor adicionado por trabalhador, onde o valor adicionado é o valor de vendas abatido o consumo intermediário de bens e serviços. Esta é a forma mais comum e que será empregada aqui.

A grande limitação do valor adicionado é a não inclusão da remuneração dos fatores de produção capital e trabalho. A produtividade total dos fatores mensura a produção em relação ao uso de matérias-primas e de fatores de produção como capital e trabalho. Alterações na relação capital/trabalho na tecnologia aumentam a produtividade medida como valor adicionado por trabalhador, mesmo que a produtividade total dos fatores não se altere. A grande dificuldade de seu uso reside na necessidade de mensurar os serviços do capital, o que, no mínimo e, mesmo sob hipóteses fortes, requer o cálculo do estoque de capital. Para a PAS a informação sobre investimentos em edificações e equipamentos passou a ser realizada a partir de 2002 apenas. Para a PIA a informação está disponível apenas para empresas maiores de 30 funcionários (estrato certo). Devido às dificuldades de mensuração do estoque de capital, focamos no uso do valor adicionado por trabalhador como medida de produtividade.

Para mensuração da produtividade ao longo do tempo faz-se mister proceder no deflacionamento correto. Em vez de empregar um deflator para o valor adicionado em si, as boas práticas - Schreyer \& Pilat (2001) - indicam o uso de um deflator de cada elemento (receitas e elementos dos custos operações). Isso pode ser feito a partir de dados das Contas Nacionais, que trazem informações de deflatores.

Para o cálculo da medida de produtividade utilizando dados da PAS, que traz uma desagregação setorial mais detalhada do que as Contas Nacionais, foram empregados deflatores de setores compatíveis das Contas Nacionais. A escolha de deflatores das Contas Nacionais, mesmo sob risco de erros de medida pelo uso do mesmo deflator para mais de um setor, está no custo da alternativa de obter um deflator para cada setor a partir de uma adaptação de produtos constantes nos índices de preço ao consumidor. Alguns serviços para empresas não estariam contemplados nos índices de preços ao consumidor, limitando a análise.

Em síntese, as medidas de produtividade empregadas neste trabalho vêm das Contas Nacionais (valor adicionado por ocupação, nos 56 setores das Contas Nacionais por ocupação) ou da PAS (valor adicionado, como diferença entre receita e consumo de bens e serviços intermediários, por pessoal ocupado em 31/12, nos subsetores cobertos pela PAS).

Essas medidas de produtividade agregada e seus componentes setoriais, ao longo do tempo, serão decompostos para descrever de modo mais preciso a sua dinâmica e com isso entender seus padrões de crescimento.

As decomposições partem de identidades das definições de produtividade como valor adicionado $(Y)$ por trabalhador, ou emprego $(N): P_{t}=\frac{Y_{t}}{N_{t}}$. O produto agregado pode ser escrito como a soma do valor adicionado em vários setores ou gruposi $i=1, \ldots, n, Y_{t}=\sum_{i=1}^{n}$, e a fração do emprego agregado no setor $i$ pode ser escrito como $w_{i t}=\frac{N_{i t}}{N_{t}}$. Assim, a produtividade agregada pode ser escrita como a soma da produtividade em cada grupo $i$, ponderada pelo peso 
de cada grupo no total: $P_{t}=\frac{Y_{t}}{N_{t}}=\sum_{i}\left(\frac{Y_{i t}}{N_{i t}}\right)\left(\frac{N_{i t}}{N_{t}}\right)=\sum_{i} P_{i t} w_{i t}$.

Ao analisarmos a mudança da produtividade em dois períodos, temos:

$$
\Delta P_{t}=P_{t}-P_{t-1}=\sum_{i} P_{i t} w_{i t}-P_{i t-1} w_{i t-1}
$$

Fica claro que a variação depende das mudanças de produtividade em cada setor (desempenho setorial) e do peso de cada setor no emprego total (estrutura).

Há dois modos de decompor essa variação no tempo em seus elementos (estrutura e desempenho, ou parcelas de emprego e produtividade intra-setorial). O primeiro usa uma produtividade total artificial, também dita contra-factual. O segundo toma como o padrão de comparação o período inicial, mas explicita uma covariância entre os termos. O primeiro método isola o efeito da estrutura no crescimento da produtividade estimando o crescimento da produtividade agregada em situação hipotética em que a estrutura produtiva não muda. Isso reflete uma hipótese comportamental de ortogonalidade entre mudança estrutural e crescimento que pode ou não ser verdade e pode ser verificada no segundo método.

Usando como base de comparação as novas produtividades e a estrutura produtiva inicial $w_{i t-1}$, temos a produtividade contrafactual $P^{*}=\sum_{i} P_{i t} w_{i t-1}$. Somando e subtraindo o novo termo e arranjando, temos $\Delta P_{t}=P_{t}-P_{t-1}=$ $\left(P_{t}-P^{*}\right)+\left(P^{*}-P_{t-1}\right)$ que leva à expressão:

$$
\Delta P_{t}=\sum_{i} \Delta P_{i t} w_{i t}-\Delta w_{i t-1} P_{i t-1}
$$

onde $\Delta P_{i t}=P_{i t}-P_{i t-1}$ e $\Delta w_{i t}=w_{i t}-w_{i t-1}$.

Esta é a ideia, por exemplo, da decomposição de Oaxaca1994-Blinder ${ }^{3}$. A atratividade da decomposição reside na interpretação dos termos. Se não há crescimento da produtividade em cada grupo $i$, o primeiro termo à direita é zero e toda a variação da produtividade agregada vem de diferenças na distribuição do emprego ao longo do tempo, nos grupos $i$, ou seja, realocação de emprego ou mudanças de estrutura. Por outro lado, se os pesos $w_{i}$ não mudam ao longo do tempo, o segundo termo à direita é zero e toda a variação da produtividade pode ser atribuída a variações de produtividade em cada grupo $i$. Com isso dividimos a variação da produtividade em efeitos da produtividade intrassetorial ou de eficiência ou de desempenho (primeiro termo); e da realocação do emprego, inter-setorial ou efeito composição ou estrutura (segundo termo).

Uma grande crítica a esse método é que se for utilizada a forma alternativa para $P^{*}=\sum_{i} P_{i t-1} w_{i t}$, os resultados podem diferir bastante. Visto de outra forma, veja que o primeiro termo do lado direito usa como base de ponderação os pesos no período inicial, enquanto que o segundo termo usa como base de ponderação no somatório a produtividade no período final. Se ao longo do tempo $\mathrm{P}$ ou $\mathrm{w}$ variam de modo significativo ou associado, a mudança de base de comparação pode gerar resultados até contraditórios de tão diferentes.

\footnotetext{
${ }^{3}$ Alternativamente, podemos usar $P^{*}=\sum_{i} P_{i t-1} w_{i t}$, de forma que temos $\Delta P_{t}=\sum_{i}\left(P_{i}-P_{i t-1}\right) w_{i t}+$ $\sum_{i}\left(w_{i}-w_{i t-1}\right) P_{i t}$.
} 
Isso não é um problema novo na literatura econômica e é geralmente associado à análise de números-índices. O problema da base de comparação pode ser entendido didaticamente por meio do exemplo de uma variação de 50 para 100 . Se tomarmos como base o valor de 50, o aumento percentual é de $100 \%$. Mas se tomarmos como base o valor de 100, a queda percentual é de $50 \%$.

Outra crítica mais forte está na hipótese de construção do contrafactual utilizado para isolar os efeitos da estrutura. Implícito no desenho do contrafactual é a hipótese de que a variação da estrutura não está associada à variação da produtividade e com isso a escolha da base de comparação não deveria alterar sistematicamente os resultados. A hipótese de ortogonalidade entre estrutura e produtividade pode ser irrealista e não deveria ser imposta pelo método de mensuração.

Para evitar esses problemas, foram propostas na literatura duas alternativas. A primeira, menos comum, que tenta solucionar o problema da base de comparação, emprega valores médios para comparação (Van Ark et al. 2003):

$$
\Delta P_{t}=\sum_{i}\left(P_{i t}-P_{i t-1}\right) w^{*}+\sum_{i}\left(w_{i t}-w_{i t-1}\right) P^{*}
$$

onde $P_{i}^{*}=\frac{P_{i t}+P_{i t-1}}{2}$ e $w_{i}^{*}=\frac{w_{i t}+w_{i t-1}}{2}$.

A segunda e mais popular, força o uso do mesmo período como base de comparação e não impõe a ortogonalidade entre mudanças estruturais e crescimento da produtividade. Como grande vantagem, não há necessidade de imposição de um contrafactual (seja $\sum_{i} P_{i t-1} w_{i t}$ ou $\sum_{i} P_{i t} w_{i t-1}$ ). Isso gera um termo adicional na decomposição, isto é, um terceiro termo que leva em conta a covariância entre as variáveis ${ }^{4}$.

$$
\Delta P_{t}=\underbrace{\sum_{i} \Delta P_{i t} w_{i t-1}}+\underbrace{\sum_{i} \Delta w_{i t} P_{i t-1}}+\underbrace{\sum_{i} \Delta P_{i t} \Delta w_{i t}}
$$

(A)

(B)

(C)

A divisão em três partes traz uma interpretação interessante. Se a decomposição anterior impõe uma hipótese de independência entre movimentos de produtividade e mudança nos pesos, esta decomposição (4) deixa claro que pode haver um efeito de covariância, positivo ou negativo, entre as variáveis que compõem a produtividade agregada. Esse terceiro termo é chamado de Bônus Estrutural (vide, por exemplo, Rocha (2007)).

Até o momento consideramos apenas variações absolutas. Mas a decomposição pode ser feita em relação a variações relativas. Temos para a equação $(4)$ :

$$
\begin{aligned}
\frac{\Delta P_{t}}{P_{t-1}} & =\sum \Delta P_{i t} \frac{w_{i t-1}}{P_{t-1}}+\sum \Delta w_{i t} \frac{P_{i t-1}}{P_{t-1}}+\sum\left(\Delta P_{i t}\right)\left(\Delta w_{i t}\right) \frac{1}{P_{t-1}} \\
\frac{\Delta P_{t}}{P_{t-1}} & =\sum \frac{\Delta P_{i t}}{P_{i t-1}} \frac{P_{i t-1} w_{i t-1}}{P_{t-1}}+\sum \frac{\Delta w_{i t}}{w_{i t-1}} \frac{P_{i t-1} w_{i t-1}}{P_{t-1}} \\
& +\sum \frac{\Delta P_{i t}}{P_{i t-1}} \frac{\Delta w_{i t}}{w_{i t-1}} \frac{P_{i t-1} w_{i t-1}}{P_{t-1}}
\end{aligned}
$$

\footnotetext{
${ }^{4}$ Matematicamente, a expressão pode ser obtida por meio da soma e subtração dos seguintes termos em colchetes, na diferença de produtividade: $\Delta P_{t}=\sum_{i} P_{i t} w_{i t}-\sum_{i} P_{i t-1} w_{i t-1}+$ $\left[\sum_{i} P_{i t} w_{i t-1}-\sum_{i} P_{i t} w_{i-1 t}\right]+\left[\sum_{i} P_{i t-1} w_{i t}-\sum_{i} P_{i t-1} w_{i}\right]+\left[\sum_{i} P_{i t-1} w_{i t-1}-\sum_{i} P_{i t-1} w_{i t-1}\right]$.
} 


$$
\begin{aligned}
g_{t} & =\frac{\Delta P_{t}}{P_{t-1}}, g_{t}^{W} \frac{\Delta w_{t}}{w_{t-1}}, g_{i t}^{P} \frac{\Delta P_{i t}}{P_{i t-1}} \mathrm{e} \\
\text { Denominando } \omega_{i t-1} & =\frac{P_{i t-1} w_{i t-1}}{P_{t-1}}=\left(\frac{Y_{i t-1}}{N_{i t-1}}\right)\left(\frac{N_{i t-1}}{N_{t-1}}\right)\left[\frac{1}{\frac{Y_{t-1}}{N_{t-1}}}\right] \text { onde } \omega \text { é a parcela } \\
& =\frac{Y_{i t-1}}{Y_{t-1}}
\end{aligned}
$$

do setor $i$ na produção agregada, a equação pode ser escrita como:

$$
\begin{aligned}
& g_{t}=\sum g_{i t}^{P} \omega_{i t-1}+\sum g_{i t}^{W} \omega_{i t-1}+\sum g_{i t}^{W} g_{i t}^{P} \omega_{i t-1} \\
& g_{t}=\sum\left(g_{i t}^{W}+g_{i t}^{P}+g_{i t}^{W} g_{i t}^{P}\right) \omega_{i t-1}
\end{aligned}
$$

Vale a pena notar que a relação entre estrutura e produtividade pode ser mensurada por meio de uma decomposição da produtividade para um certo ano, proposta por Olley \& Pakes (1996). Nela a influência da estrutura na produtividade é mensurada por meio de um termo de covariância entre estrutura e produtividade. Ao contrário da decomposição (4), a decomposição é aplicada para uma data específica, sem mensurar a variação de produtividade. $\mathrm{O}$ artifício utilizado pelos autores está na diferença entre a produtividade agregada, que é uma média ponderada das produtividades setoriais, e uma produtividade contrafactual na qual todos os setores têm a mesma importância. Essa produtividade é calculada por meio da média simples das produtividades setoriais $P_{t}^{*}$. O uso dessa produtividade contrafactual gera um termo que mede a diferença entre a produtividade observada e a contrafactual, que é a covariância entre produtividade e estrutura. O uso desta produtividade contrafactual gera um termo que mede a diferença entre a produtividade observada e a contrafactual, que é a covariância entre produtividade e estrutura.

$$
P_{t}=P_{t}^{*}+\sum\left(w_{i t-1}-w_{t}^{*}\right)\left(P_{i t}-P_{t}^{*}\right)
$$

Um sinal positivo do segundo termo indicaria uma associação positiva (estática) entre estrutura e produtividade. Os autores interpretam o sinal positivo como indicativo de eficiência alocativa, em que setores mais produtivos são aqueles com maior importância na estrutura da economia.

\section{Evolução da produtividade do trabalho: uma comparação entre Serviços e Indústria}

Como visto acima, a discussão da evolução da produtividade do trabalho no Brasil acompanhou sua evolução, com crescimento na década de 1970, estagnação na década de 1980, crescimento durante as reformas liberalizantes da primeira metade dos anos 1990 e estagnação posterior.

Tomando as Contas Nacionais do IBGE como fonte básica de dados, e medindo a produtividade a preços constantes, a partir do duplo deflacionamento de produção e consumo intermediário, podemos ter uma visão atualizada da produtividade do trabalho após 1996, ano de início da análise neste trabalho e da série de dados setoriais a preços constantes nas novas Contas Nacionais.

Na Tabela 1 observa-se que o PIB cresceu de modo diferenciado ao longo do tempo, com pequeno crescimento anual no período 1996 a 2002 e uma aceleração do crescimento de 2002 a 2009 (último ano disponível). A experiência setorial reflete o agregado ${ }^{5}$. Após 2002, o Comércio apresentou o maior

\footnotetext{
${ }^{5}$ Utilizamos uma agregação dos setores das Contas Nacionais similar à empregada nas Contas Regionais pelo IBGE, a saber: Agropecuária e Recursos Naturais: Agrop, Extr.Mineral,
} 
crescimento e os Serviços o terceiro maior crescimento, atrás da Agricultura e Indústria Extrativa. Ao contrário de outros países, o crescimento pós 1996 no Brasil dependeu mais dos serviços do que da indústria, como também observou Oliveira (2011).

Tabela 1: Crescimento do PIB

\begin{tabular}{|c|c|c|c|c|c|}
\hline Ano & Agric e Extr & Ind e Ccivil & Com & Svc & Total \\
\hline $2002-2009$ & $24,5 \%$ & $17,3 \%$ & $33,6 \%$ & $28,6 \%$ & $26,4 \%$ \\
\hline 1996-2002 & $32,1 \%$ & $4,7 \%$ & $4,1 \%$ & $16,7 \%$ & $13,2 \%$ \\
\hline
\end{tabular}

A Tabela 2 traz a evolução da produtividade do trabalho. O crescimento da produtividade foi bastante heterogêneo entre os grandes setores e ao longo do tempo. Enquanto a produtividade agregada caiu entre 1996 e 2002 a preços constantes, a mesma apresentou um crescimento modesto de cerca de $8 \%$ nos sete anos seguintes, ou cerca de $1 \%$ a.a. Como os valores da Tabela 2 referem-se aos valores da Tabela 1 descontados o crescimento do emprego, aproximadamente, vemos o reflexo das alterações de intensidade do uso do trabalho no comércio e serviços.

Tabela 2: Crescimento da Produtividade do Trabalho

\begin{tabular}{lcccrr}
\hline Ano & Agric e Extr & Ind e Ccivil & Com & \multicolumn{1}{c}{ Svc } & Total \\
\hline $2002-2009$ & $27,4 \%$ & $-6,5 \%$ & $13,6 \%$ & $4,6 \%$ & $7,7 \%$ \\
$1996-2002$ & $34,4 \%$ & $-5,8 \%$ & $-17,1 \%$ & $-5,1 \%$ & $-1,4 \%$ \\
\hline Fonte: cálculos dos autores baseados nas Contas Nacionais IBGE (TRU). \\
Valores a preços constantes de 2008. Vide Tabela 1. \\
Produtividade do Trabalho = Valor Adicionado / Emprego.
\end{tabular}

A intensidade de uso do trabalho, a estrutura produtiva e os níveis de produtividade de cada grande setor podem ser vistos nas Tabelas 3,4 e 5. Ao longo do período 1996 a 2009 a importância relativa de cada setor no PIB não mudou, sendo os Serviços o maior setor da economia, seguido pela Indústria de Transformação e Construção Civil, Comércio e por fim a Agricultura e Extrativa Mineral. No emprego (medida por ocupações nas Contas Nacionais) o ranking se altera com a Agricultura e Extrativa Mineral como segundo setor mais importante no emprego. A tendência é de queda no emprego nesse setor, chegando em 2009 com emprego menor, relativamente, do que a Indústria. Uma das razões da grande importância dos serviços está no setor público, que nas contas nacionais é totalmente alocado, nas suas atividades diretas e indiretas não industriais no setor de Serviços.

Quanto à produtividade em si, a Tabela 5 mostra que os setores mais produtivos (maior valor adicionado por ocupação) são a Indústria e os Serviços,

Extr.Petróleo-Gás, Ind.Minerais Não metálicos; Indústria: Ind. Transf, SIUP e Constr. Civil; Comércio: comércio; Serviços: serviços em todas classificações (exceto SIUP), transporte, comunicações, setor público. A alocação da indústria extrativa mineral (Extr.Mineral, Extr.Petróleo-Gás, Ind.Minerais Não metálicos) no grande setor da indústria não altera as tendências verificadas, , como pode ser visto nas tabelas do Anexo. 
Tabela 3: Estrutura Produtiva: Parcela de cada setor no PIB

\begin{tabular}{cccccc}
\hline Ano & Agric e Extr & Ind e Ccivil & Com & Svc & Total \\
\hline 2009 & $9.5 \%$ & $22.7 \%$ & $12.4 \%$ & $55.4 \%$ & $100.0 \%$ \\
2002 & $9.6 \%$ & $24.4 \%$ & $11.7 \%$ & $54.3 \%$ & $100.0 \%$ \\
1996 & $8.2 \%$ & $26.3 \%$ & $12.8 \%$ & $52.6 \%$ & $100.0 \%$ \\
\hline
\end{tabular}

Fonte: cálculos dos autores baseados nas Contas Nacionais IBGE (TRU).

Valores a preços constantes de 2008. Vide Tabela 1.

Produtividade do Trabalho = Valor Adicionado $/$ Emprego

Tabela 4: Estrutura Produtiva: Parcela de cada setor no Emprego

\begin{tabular}{cccccc}
\hline Ano & Agric e Extr & Ind e Ccivil & Com & Svc & Total \\
\hline 2009 & $18,3 \%$ & $19,6 \%$ & $16,5 \%$ & $45,6 \%$ & $100,0 \%$ \\
2002 & $21,9 \%$ & $18,3 \%$ & $16,4 \%$ & $43,4 \%$ & $100,0 \%$ \\
1996 & $25,6 \%$ & $18,9 \%$ & $15,0 \%$ & $40,6 \%$ & $100,0 \%$ \\
\hline
\end{tabular}

Fonte: cálculos dos autores baseados nas Contas Nacionais IBGE (TRU).

Valores a preços constantes de 2008. Vide Tabela 1.

Produtividade do Trabalho = Valor Adicionado $/$ Emprego.

Tabela 5: Produtividade do Trabalho em cada setor (em mil $\mathrm{R} \$)$

\begin{tabular}{cccccc}
\hline Ano & Agric e Extr & Ind e Ccivil & Com & Svc & Total \\
\hline 2009 & 13,8 & 30,8 & 20,1 & 32,3 & 26,6 \\
2002 & 10,9 & 32,9 & 17,7 & 30,9 & 24,7 \\
1996 & 8,1 & 34,9 & 21,4 & 32,5 & 25,0 \\
\hline
\end{tabular}

Fonte: cálculos dos autores baseados nas Contas Nacionais IBGE

(TRU).

Valores a preços constantes de 2008. Vide Tabela 1.

Produtividade do Trabalho = Valor Adicionado / Emprego.

com cerca de R \$30mil a R \$35mil por ocupação a preços de 2008. Em 2009, em realidade, os serviços apresentavam produtividade maior do que a Indústria. Importante notar que a produtividade da Agricultura, apesar do grande crescimento, ainda está em um patamar de menos da metade do que a Indústria ou Serviços. Por fim, o setor de comércio apresenta valores intermediários entre a indústria e serviços e a agropecuária.

As tabelas acima servem para colocar a discussão em perspectiva mais sólida. Enquanto o setor de serviços não é um setor de baixa produtividade em relação à indústria, a experiência recente no Brasil mostra um crescimento da produtividade, quando da retomada de crescimento a partir de 2002-2003 em setores outros que não a indústria, como os serviços.

As experiências díspares dos setores, em particular da indústria e dos serviços, chamam a atenção para tentar entender fatores que contribuiriam para essa dinâmica. Dentro do escopo deste trabalho de documentar a dinâmica e apresentar uma visão inicial sobre o tema, são explorados argumentos associados à estrutura e desempenho intrassetorial como explicações para as diferentes trajetórias dos serviços e indústria. Outros fatores relevantes para 
a evolução da produtividade como inovação, grau de competição interna e externa e política tributária são deixados para trabalhos futuros apenas por questões de organização e escopo deste trabalho.

Explicações imediatas para explicar diferenças entre serviços e indústria em qualquer país estão, por exemplo, em Rodrik (2014). A indústria está exposta ao comércio internacional e sofre efeitos da abertura comercial (antes do período em análise) e, principalmente, do câmbio, que altera preços relativos frente a produtos importados. Já os serviços, grosso modo, estão isolados deste efeito do câmbio e comércio exterior, mas são bastante sensíveis à trajetória da renda doméstica e sua distribuição. De qualquer forma, essas explicações podem ser avenidas interessantes de pesquisa, se os movimentos agregados forem homogêneos dentro dos setores. Isto será investigado abaixo, por meio das decomposições de crescimento de produtividade.

Assim, a seguir focaremos a decomposição da dinâmica do crescimento utilizando as mesmas Contas Nacionais. Posteriormente, passamos à análise de dados do setor de Serviços de modo mais detalhado, por meio da Pesquisa Anual de Serviços (PAS), do IBGE, para tentar isolar o efeito do setor público na evolução descrita acima e obter também uma desagregação mais fina dos setores dos Serviços, reconhecidamente heterogêneo por vários autores (Oliveira 2011, Silva 2006).

Utilizando a decomposição (5), com um termo de covariância, para representar melhor a dinâmica da produtividade, vemos na Tabela 6 que o crescimento da produtividade na economia no período 2002-2009 deu-se basicamente pela soma dos efeitos intrassetorial (crescimento da produtividade nos setores) e de estrutura (maior crescimento relativo na parcela no emprego dos setores inicialmente mais produtivos). Não se verificou bônus estrutural.

A diferente experiência dos períodos 1996-2002 e 2002-2009 pode ser entendida, no primeiro período, pelo desempenho negativo de setores com grande importância na ocupação (efeito intra-setor negativo) e, principalmente, pelo forte efeito de covariância. Ou seja, a queda da produtividade no período 1996-2002 deve-se à realocação negativa em que os setores com maiores quedas na produtividade tiveram expansão do emprego relativo, enquanto que os setores com aumentos de produtividade tiveram redução relativa da importância na ocupação. Em grande parte vemos a importância do emprego (e não da expansão da produção) como fator relevante para entender a evolução do valor adicionado por trabalhador.

Tabela 6: Decomposição (5) da variação da produtividade (valor adicionado por ocupação) - Brasil — Contas Nacionais

\begin{tabular}{lcccc}
\hline Período & Total & Intrassetor & Estrutural & Covariância \\
\hline $2002-2009$ & $7,7 \%$ & $3,5 \%$ & $5,9 \%$ & $-1,7 \%$ \\
$1996-2002$ & $-1,4 \%$ & $-1,7 \%$ & $7,7 \%$ & $-7,4 \%$ \\
\hline Fonte: cálculos dos autores baseados nas Contas Nacionais IBGE (TRU) em \\
42 setores. \\
Valores a preços constantes de 2008. Vide nota Tabela 1. \\
Produtividade do Trabalho = Valor Adicionado / Emprego. \\
Para explicações sobre os termos, ver equação 5 acima.
\end{tabular}

A visão se mantém quando se emprega a decomposição (3) em valor percentual, sem termo de covariância. O desempenho negativo da evolução da 
Tabela 7: Decomposição (2) da variação da produtividade (valor adicionado por ocupação) — Brasil - Contas Nacionais

\begin{tabular}{lccc}
\hline Período & Total & Intrassetor & Estrutural \\
\hline $2002-2009$ & $7,7 \%$ & $2,7 \%$ & $5,1 \%$ \\
$1996-2002$ & $-1,4 \%$ & $-5,4 \%$ & $4,0 \%$ \\
\hline Fonte: cálculos dos autores baseados nas Contas Nacionais \\
IBGE (TRU) em 42 setores. \\
Valores a preços constantes de 2008. Vide nota Tabela 1. \\
Produtividade do Trabalho = Valor Adicionado / Emprego. \\
Para explicações sobre os termos, ver equação 5 acima.
\end{tabular}

produtividade no período 1996-2002 foi construído pela queda de produtividade, em setores de destaque na estrutura produtiva brasileira. A queda da produtividade não foi maior nesse período inicial já que as mudanças estruturais foram pró-produtividade, ou seja, de aumento de importância no emprego de setores que tinham produtividade acima da média. Este é um ponto importante que vai contra os temores de estagnação da produtividade da economia pela redução da importância da indústria entre 1996 e 2002.

Do ponto de vista metodológico, os resultados da Tabela 7 indicam que há relação não desprezível entre mudanças de estrutura e crescimento da produtividade nos setores, tomando a análise contrafactual do modelo (2) de ortogonalidade pouco crível. Isso é confirmado pela decomposição de Olley \& Pakes (1996), (7), que explora a associação estática entre estrutura e produtividade.

A Tabela 8 mostra que essa associação explica parte relevante da produtividade anual e que, embora este termo tenha crescido entre 2002 e 1996, ele diminuiu entre 2002 e 2009, sugerindo uma realocação na economia na direção de setores mais produtivos ao longo do tempo. Comparando com as Tabelas 6 e 7, pode-se argumentar que a redução do termo de covariância vem do crescimento dos serviços acima da média da economia, apresentando maior produtividade do que a indústria, além de responder por grande parcela do emprego.

A diferença de experiências entre períodos recomenda uma análise mais aprofundada. Para isso, contrastamos as decomposições para a indústria de transformação e para os serviços.

Tabela 8: Decomposição (7) da variação da produtividade (valor adicionado por ocupação) - Brasil - Contas Nacionais

\begin{tabular}{lccc}
\hline Período & Prod. Média & Covariância (Alocativo) & Prod. Total \\
\hline 2009 & 79,6 & $-53,0$ & 26,6 \\
2002 & 96,1 & $-71,4$ & 24,7 \\
1996 & 90,4 & $-65,4$ & 25,0 \\
\hline Fonte: cálculos dos autores baseados nas Contas Nacionais IBGE (TRU) em 42 \\
setores. \\
Valores a preços constantes de 2008. Vide nota Tabela 1. \\
Produtividade do Trabalho = Valor Adicionado / Emprego. \\
Para explicações sobre os termos, ver equação (7) acima.
\end{tabular}

Focando o setor de serviços apenas, com a limitação da pequena desagre- 
gação do mesmo em poucos setores das Contas Nacionais, vemos um padrão similar para o período de 1996 a 2002 da economia como um todo, com o efeito intrassetorial negativo, um efeito composição mitigando a queda e ganho de importância de subsetores com maiores quedas de produtividade. Já para o período 2002 a 2009 o crescimento da produtividade dos serviços foi quase que completamente explicado pelo crescimento intrasetorial da produtividade, em que o componente de estrutura teve contribuição nula para o crescimento da produtividade e o bônus estrutural, apesar de negativo, foi pequeno. Interessante notar que apenas nesse ponto temos uma diferença do setor de serviços (Tabela 9) da experiência da economia como um todo, como visto na Tabela 6.

Tabela 9: Decomposição da variação da produtividade nos serviços

\begin{tabular}{lcccc}
\hline Período & Total & Intrasetor & Estrutural & Covariância \\
\hline $2002-2009$ & $4,6 \%$ & $5,6 \%$ & $-0,3 \%$ & $-0,7 \%$ \\
$1996-2002$ & $-5,1 \%$ & $-2,0 \%$ & $7,6 \%$ & $-10,7 \%$ \\
\hline Fonte: cálculos dos autores baseados nas Contas Nacionais IBGE (TRU) em \\
42 setores. \\
Valores a preços constantes de 2008. Vide nota Tabela 1. \\
Produtividade do Trabalho = Valor Adicionado / Emprego. \\
Para explicações sobre os termos, ver equação 5 acima.
\end{tabular}

Tabela 10: Decomposição da variação da produtividade na indústria de transformação

\begin{tabular}{lcccc}
\hline Período & Total & Intrasetor & Estrutural & Covariância \\
\hline $2002-2009$ & $-6,5 \%$ & $-8,3 \%$ & $3,4 \%$ & $-1,6 \%$ \\
$1996-2002$ & $-5,8 \%$ & $-1,5 \%$ & $-0,3 \%$ & $-4,0 \%$ \\
\hline Fonte: cálculos dos autores baseados nas Contas Nacionais IBGE (TRU) em \\
42 setores. \\
Valores a preços constantes de 2008. Vide nota Tabela 1. \\
Produtividade do Trabalho = Valor Adicionado / Emprego. \\
Para explicações sobre os termos, ver equação (5) acima.
\end{tabular}

Ao passar para a decomposição da variação da produtividade da indústria de transformação no período 1996-2009, na Tabela 10, é importante de ter em mente o desempenho negativo da produtividade em ambos sub-períodos. Nota-se que o desempenho intrassetorial nos subsetores da indústria de transformação foi negativo em ambos os períodos, assim como o termo de covariância. Já o componente de realocação estrutural foi quase nulo no primeiro período, mas positivo no segundo período, mitigando o expressivo desempenho negativo na média dos setores da indústria.

Para completar a análise de decomposição na comparação entre indústria e serviços, nas Tabelas 11 e 12 abaixo apresentamos as decomposições da produtividade anual em componentes alocativo e intrassetorial, a partir da decomposição Olley1996-Pakes. Tanto na indústria como nos serviços, o efeito de covariância é negativo e relevante na decomposição, chegando a ser maior do que a produtividade agregada (total) do setor de serviços. As trajetórias dos termos são diferentes entre indústria e serviços. Enquanto nos serviços o 
termo de covariância aumentou entre 2002 e 2009, mitigando o aumento médio da produtividade nos setores, na indústria, ao longo do tempo, o efeito de covariância contribuiu para uma menor queda da produtividade. Entre setores, a tendência da produtividade média foi diferente entre 2002 e 2009, com aumento nos serviços e queda na indústria.

Tabela 11: Decomposição (7) da produtividade nos serviços

\begin{tabular}{lccc}
\hline Período & Prod. Média & Covariância (Alocativo) & Prod. Total \\
\hline 2009 & 86,8 & $-54,5$ & 32,3 \\
2002 & 77,5 & $-46,6$ & 30,9 \\
1996 & 82,1 & $-49,6$ & 32,5 \\
\hline
\end{tabular}

Fonte: cálculos dos autores baseados nas Contas Nacionais IBGE (TRU) em 42 setores.

Valores a preços constantes de 2008. Vide nota Tabela 1.

Produtividade do Trabalho = Valor Adicionado / Emprego.

Para explicações sobre os termos, ver equação (7) acima.

Tabela 12: Decomposição (7) da produtividade na indústria de transformação

\begin{tabular}{|c|c|c|c|}
\hline Período & Prod. Média & Covariância (Alocativo) & Prod. Total \\
\hline 2009 & 57,4 & $-26,6$ & 30,8 \\
\hline 2002 & 67,0 & $-34,1$ & 32,9 \\
\hline 1996 & 66,9 & $-32,0$ & 34,9 \\
\hline
\end{tabular}

A evolução negativa da produtividade da indústria no longo prazo já foi explicada por alguns autores como Baumol et al. (1985). pela mudança estrutural da economia para os serviços e crescimento lento da produtividade na indústria. Inicialmente, vimos na seção anterior que os serviços no Brasil não apresentam baixa produtividade nem estagnação. Para confirmar a irrelevância da doença de custos para o caso brasileiro focamos a importância dos serviços no consumo intermediário no Brasil.

As tabelas de recursos e usos das Contas Nacionais trazem um importante indicador da importância dos serviços na atividade industrial, a saber, a parcela do consumo intermediário da indústria que vem de serviços. Na Figura 1 observa-se uma trajetória de queda até 2005, quando então a importância do consumo intermediário de serviços na estrutura de custos intermediários da indústria aumenta, terminando em patamar um pouco superior ao de 1996. As tendências se verificam tanto para a indústria de transformação como para indústria como um todo (inclusive extrativa mineral).

As tendências apresentadas na Figura 1 em nada se associam com as tendências da produtividade (valor adicionado por ocupação) verificadas acima, permitindo descartar uma associação entre o peso dos serviços no consumo intermediário da indústria e a evolução da produtividade da indústria. 


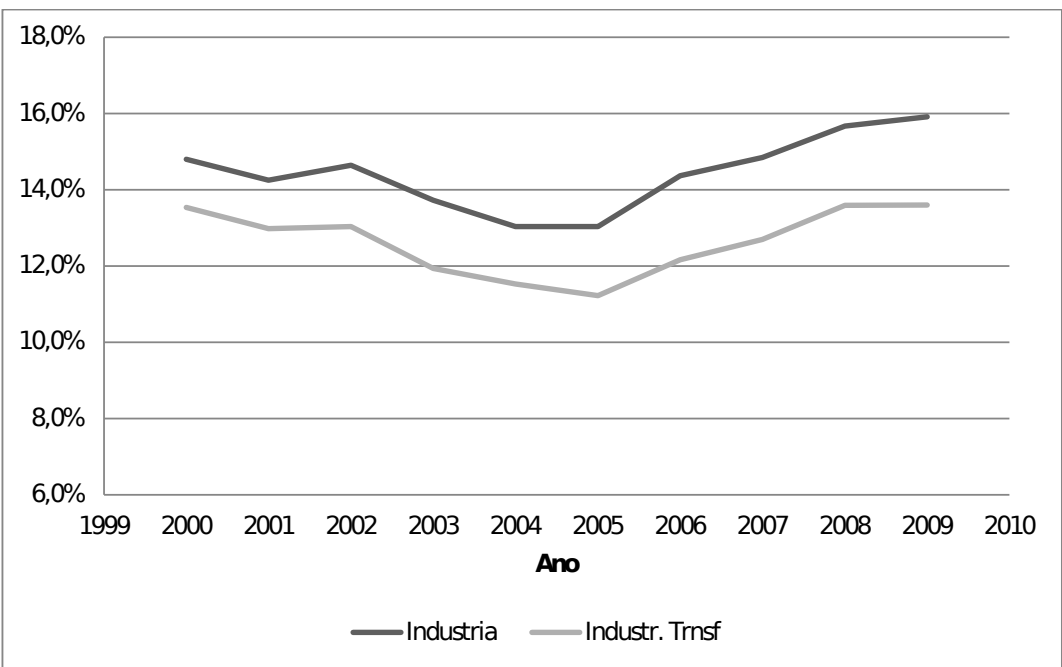

Fonte: cálculo dos autores baseados nas Contas Nacionais IBGE (TRU).

Figura 1: Parcela do consumo intermediário da indústria advindo de serviços $(\mathrm{CN})$

A própria tendência de crescimento no peso dos serviços no consumo intermediário da indústria no período 2005-2009 não pode ser tomada, per se, como indicativo de problemas no setor. Como a análise se refere a uma parcela do gasto, um aumento dessa parcela, vis a vis o consumo de matérias-primas ou energia, por exemplo, pode estar associado a realidades bastante distintas. Por um lado, o aumento da parcela do gasto com serviços pode indicar que o custo dos mesmos está maior e dada sua demanda inelástica no processo produtivo, verifica-se um aumento dos gastos. Por outro, o aumento da parcela dos custos com serviços pode indicar uma maior produtividade desses serviços, o que induziria um progresso técnico viesado a favor do uso desses fatores mais produtivos em relação às matérias-primas e/ou energia, fazendo com que a parcela de gastos em serviços aumentasse, pelo maior uso por unidade produzida.

Veja que as explicações são contraditórias e partem de comportamentos diferentes da produtividade dos serviços. No primeiro caso a produtividade estaria estagnada, com preços estáveis ou crescentes, o que levaria a um aumento de gastos, mesmo com manutenção de quantidade de serviço por unidade produzida. No segundo caso a produtividade dos serviços estaria crescendo, tornando-se mais atrativo (com efeitos indeterminados nos preços dos serviços) e com maior quantidade de serviços por unidade produzida. Vemos nas tabelas acima que a avaliação de produtividade dos serviços seguiu a tendência de queda e recuperação similar à parcela do consumo intermediário. Isso sugere maior credibilidade para a explicação de que os serviços não foram responsáveis pela redução da produtividade na indústria.

Além da análise acima, uma forma indireta de distinguir entre as hipóteses alternativas citadas está no detalhamento da evolução da produtividade das atividades de serviços em si. Infelizmente a análise baseada nas Contas $\mathrm{Na}$ cionais traz uma agregação muito forte dos subsetores dos serviços, além de incorporar, com grande peso, a Administração Pública. Para uma visão mais detalhada dos serviços, emprega-se fonte alternativa de dados, a PAS, como 
mencionado acima.

A Tabela 13 apresenta a evolução da produtividade dos subsetores dos serviços no período de 2002 a 2009. Como pode ser visto, o setor de serviço é subdividido em sete sub-setores: serviços prestados às famílias, serviços de informação, serviços prestados às empresas, transportes, serviços auxiliares aos transportes e correio, atividades imobiliárias e de aluguel de bens móveis e imóveis, serviços de manutenção e reparação e, por fim, outras atividades de serviços. A produtividade de cada subsetor é bastante heterogênea, indo de $\mathrm{R} \$ 167,6$ mil em telecomunicações (serviços de informação) até $\mathrm{R} \$ 29,7$ mil nos serviços prestados às famílias.

A produtividade dessas atividades de serviços como um todo cresceu $11,64 \%$, passando de $\mathrm{R} \$ 35,9$ mil em 2002 para $\mathrm{R} \$ 40,1$ mil em 2009. Nota-se que todos os sub-setores apresentaram crescimento da produtividade com exceção dos serviços de informação e dos transportes, serviços auxiliares aos transportes e correio.

Tabela 13: Produtividade dos Serviços — PAS em Mil R\$ de 2008

\begin{tabular}{lrrrrrrrr}
\hline Subsetor & 2002 & 2003 & 2004 & 2005 & 2006 & 2007 & 2008 & 2009 \\
\hline 1. Total & 35,9 & 37,0 & 37,8 & 38,1 & 37,2 & 39,6 & 40,7 & 40,1 \\
2. Serviços prestados às famílias & 11,7 & 12,2 & 12,4 & 14,4 & 13,7 & 14,9 & 15,3 & 16,1 \\
3. Serviços de informação & 167,6 & 183,2 & 166,6 & 147,3 & 136,2 & 142,0 & 142,9 & 149,4 \\
4. Serviços prestados às empresas & 29,7 & 27,9 & 27,7 & 30,8 & 30,5 & 33,9 & 35,3 & 34,4 \\
5. Transportes, serviços auxiliares aos & 45,6 & 43,2 & 47,1 & 44,4 & 44,0 & 44,4 & 44,5 & 41,4 \\
transportes e correio & & & & & & & & \\
6. Atividades imobiliárias e de aluguel & 38,5 & 36,9 & 45,8 & 48,1 & 54,9 & 52,7 & 56,7 & 57,9 \\
de bens móveis e imóveis & & & & & & & & \\
7. Serviços de manutenção e reparação & 12,6 & 13,7 & 12,8 & 14,3 & 14,7 & 15,1 & 17,9 & 17,2 \\
8. Outras atividades de serviços & 25,6 & 30,4 & 34,4 & 34,2 & 35,9 & 42,6 & 51,8 & 50,2 \\
\hline Fonte: cálculos dos autores baseado
\end{tabular}

Fonte: cálculos dos autores baseado em compatibilização da CNAE 1.0 e CNAE 2.0.

Uma maneira útil de olhar a evolução da produtividade a partir da Tabela 13 seria adotar uma estratégia de compor os sub-setores em 3 grupos como a empregada pelo Ipea (2012), que é uma adaptação da classificação da Eurostat: o primeiro, alta tecnologia e mercado, composto pelos sub-setores de serviços de informação, serviços prestados às empresas e atividades imobiliárias e de aluguel de bens móveis e imóveis; o segundo, composto pelos serviços prestados às famílias, transportes, serviços auxiliares aos transportes e correio, e serviços de manutenção e reparação; por fim, outros que incorporariam o subsetor de outras atividades de serviços.

Tabela 14: Evolução da produtividade do trabalho — subsetores dos serviços

\begin{tabular}{lcccccccc}
\hline Grupo & 2002 & 2003 & 2004 & 2005 & 2006 & 2007 & 2008 & 2009 \\
\hline Alta tecnologia e mercado & 21,10 & 22,18 & 22,00 & 22,45 & 21,94 & 23,62 & 24,01 & 24,02 \\
Pouco intensivos em capital & 13,48 & 13,20 & 13,99 & 13,88 & 13,39 & 13,57 & 13,80 & 13,36 \\
Outros & 25,62 & 30,38 & 34,38 & 34,25 & 35,85 & 42,63 & 51,77 & 50,19 \\
\hline Fonte: cálculos dos autores baseado na PAS e em compatibilização da CNAE 1.0 e e \\
CNAE 2.0.
\end{tabular}

Na Tabela 14, observa-se que a produtividade do grupo de alta tecnologia e mercado apresenta maior produtividade do trabalho, como esperado. No 
período de 2002-2009 esse grupo perfaz um crescimento de 13,85\%. O grupo que incorpora os sub-setores considerados pouco intensivos apresentou uma leve queda de produtividade nesse período de menos de $1 \%(-0,90 \%)$. Esse resultado é interessante na medida em que evidencia que os subsetores de serviços ligados aos serviços às empresas e ao mercado (de alta tecnologia) aumentaram de modo significativo sua produtividade, retirando, mais uma vez, credibilidade da hipótese de que os serviços tenham contribuído para o desempenho ruim da produtividade na indústria.

A Tabela 15 apresenta a evolução da produtividade do setor de serviços considerando uma desagregação maior do que a observada na Tabela 13. Em geral observa-se que a evolução da produtividade no período de 2002/2009 é muito diferenciada nas divisões (sub-setores), como mencionado anteriormente. A maior taxa de crescimento atingiu $124,94 \%$ nos serviços auxiliares, financeiros, dos seguros e da previdência complementar, mais agentes de comércio e representação comercial, enquanto há vários casos de queda na produtividade, como ocorreu no serviços de telecomunicações $(-25,46 \%)$. É outra evidência da heterogeneidade interna desse setor.

Como pode ser observado, a divisão de serviços prestados às famílias apresenta aumento de produtividade para todos os segmentos que o compõe no período de 2002 a 2009. Serviços prestados às empresas e manutenção e reparação e outras atividades de serviços também foram divisões cuja evolução da produtividade foi positiva. Todos os segmentos que o compõe apresentaram aumento de produtividade, com exceção apenas de serviços de reparação de eletrodomésticos.

No período de 2002-2009 o sub-setor de transportes, serviços auxiliares aos transportes e correio a evolução da produtividade apresentou uma queda (Tabelas 9 e 10). Ao observar na Tabela 13 vemos que quase todos os segmentos contribuíram para isso, com exceção aos serviços de transporte ferroviário e metroviário e dos serviços de transporte de passageiros cujo crescimento foi de $26,99 \%$ e $1,92 \%$ respectivamente.

Em geral a evolução positiva da produtividade nas divisões dos serviços vem confirmar as observações realizadas anteriormente de forma mais agregada, com crescimento da produtividade dos serviços prestados às empresas e/ou as de alta tecnologia.

Para concluir a análise, empregamos os dados da PAS para repetir a decomposição da evolução da produtividade dos serviços, realizada nas Tabelas 9 e 10 com dados das Contas Nacionais. Duas diferenças significativas que motiva a análise são a exclusão da administração pública e uma maior desagregação do setor de serviços.

Interessante notar que a taxa de crescimento da produtividade nos setores acompanhados pela PAS para o período 2002-2009 foi maior do que a mensurada para os Serviços nas Contas Nacionais, devido à diferença de atividades econômicas envolvidas. Ao mesmo tempo, percebe-se que o desempenho positivo dos setores de serviços foi explicado pelo desempenho intrassetorial, com crescimento da produtividade na média ponderada das divisões dos Serviços na PAS respondendo por mais de $90 \%$ do crescimento agregado do setor. Há contribuição positiva do componente estrutural, de realocação próprodutividade. O termo de covariância foi negativo e menor do que os outros termos.

Comparando as Tabelas 9 e 10 com a Tabela 16, vemos que o crescimento dos serviços após 2002 em ambos os casos foi explicado pelo desempenho 


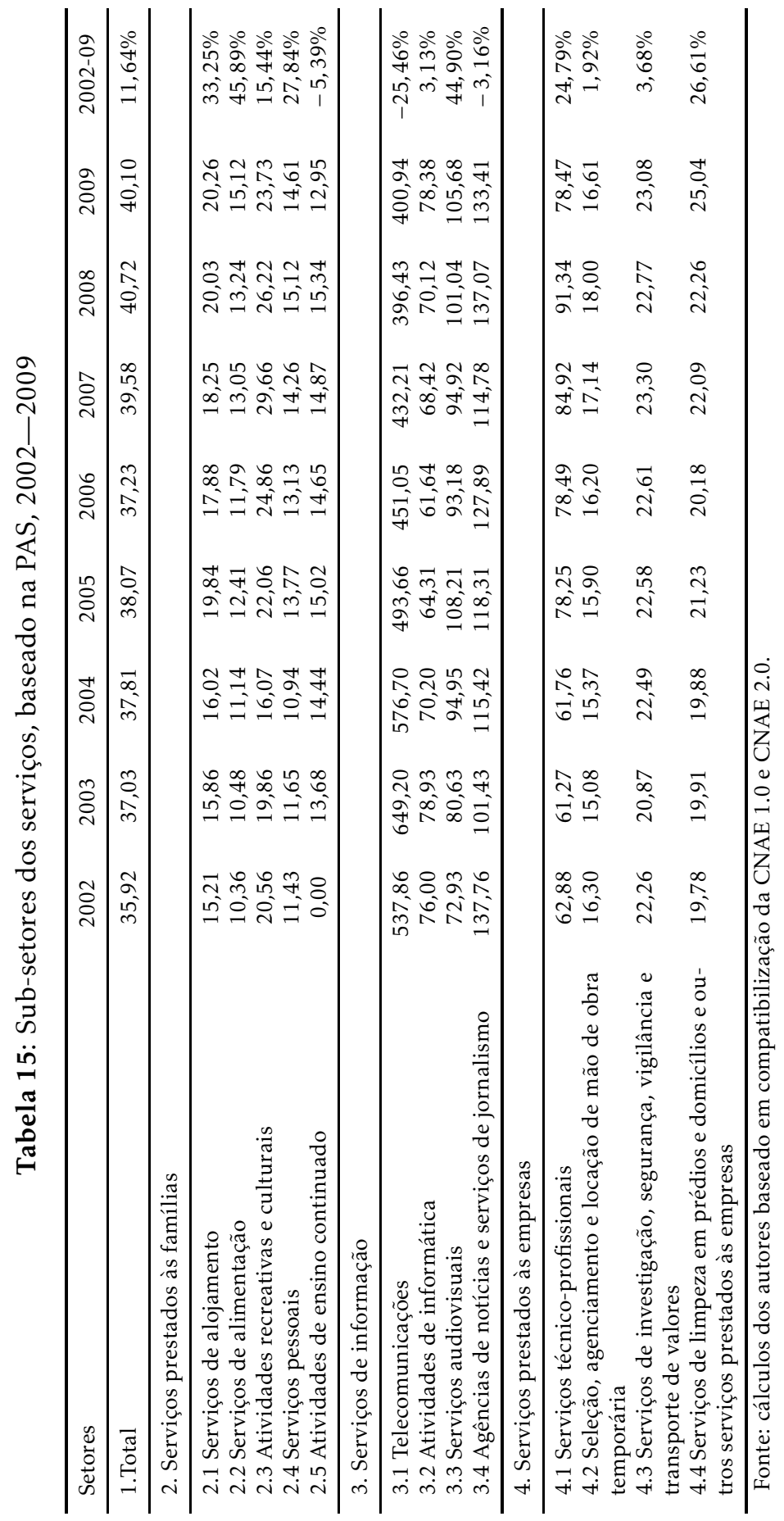




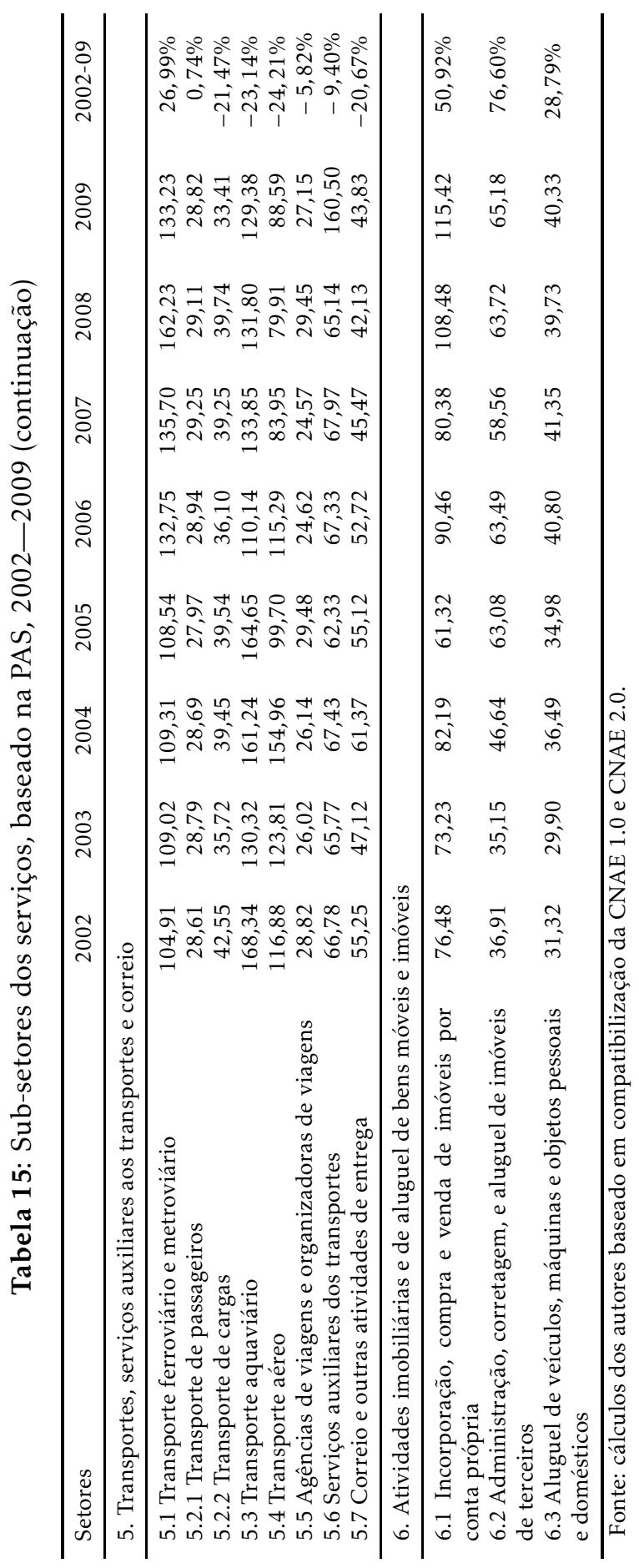


Crescimento da Produtividade no setor de serviços e da indústria no Brasil: dinâmica e heterogeneidade 421

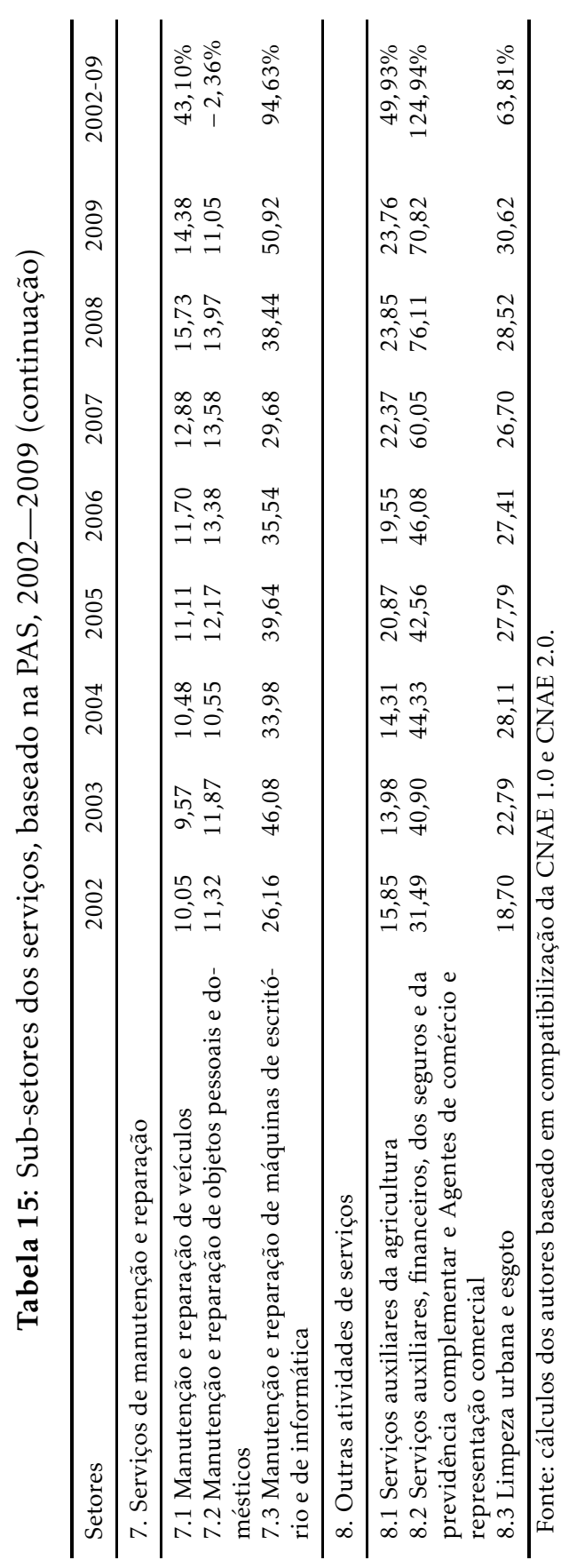


Tabela 16: Decomposição da variação da produtividade (valor adicionado por ocupação) nos serviços — PAS

\begin{tabular}{lcccc}
\hline Período & Total & Intrassetor & Estrutural & Covariância \\
\hline $2002-2009$ & $11,00 \%$ & $10,50 \%$ & $3,30 \%$ & $-2,80 \%$ \\
Importância relativa & & $94,80 \%$ & $30,20 \%$ & $-25,00 \%$ \\
\hline
\end{tabular}

Nota: Valores a preços constantes de 2008. Vide nota Tabela 1.

Produtividade do Trabalho $=$ Valor adicionado / Emprego.

Para explicações sobre os termos, ver equação (7) acima.

Fonte: cálculos dos autores baseados na PAS.

Tabela 17: Decomposição (7) da variação da produtividade (valor adicionado por trabalhador) - Brasil — PAS

\begin{tabular}{lccc}
\hline Período & Prod. Média & Covariância (Alocativo) & Prod. Total \\
\hline 2009 & 57,4 & $-26,6$ & 30,8 \\
2002 & 67,0 & $-34,1$ & 32,9 \\
1996 & 66,9 & $-32,0$ & 34,9 \\
\hline
\end{tabular}

Nota: Valores a preços constantes de 2008. Vide nota Tabela 1.

Produtividade do Trabalho $=$ Valor adicionado $/$ Emprego.

Para explicações sobre os termos, ver equação (7) acima.

Fonte: cálculos dos autores baseados na PAS.

intra-setorial. Em ambos os caso não se verificou o bônus estrutural. Por outro lado, as Contas Nacionais (Tabelas 9 e 10) e a PAS (Tabela 16) apontam para a contribuição da mudança estrutural com efeito positivo na PAS e negativo ou nulo nas CN. Uma explicação pode ser o setor público que está nas Contas Nacionais, mas não na PAS.

Como nas Tabelas 9 e 10, a importância do termo de covariância aponta para a necessidade de explorar a decomposição de Olley1996-Pakes para as divisões da PAS. Os resultados da Tabela 17 mostram que este termo de covariância é relevante e que sua trajetória cadente (ficando menos negativa) explicou grande parte do aumento da produtividade no setor, quando comparada com uma variação da produtividade média. Esses resultados apontam para uma contribuição positiva da realocação de mão de obra para a produtividade nos serviços, ao contrário da indústria.

\section{Considerações finais}

O setor de serviços vem ampliando sua participação na economia em relação aos demais setores. Ao mesmo tempo, os serviços são entendidos como um setor de baixa produtividade, o que contribuiria para a redução do crescimento da produtividade na economia e constrangeria o crescimento econômico. Este trabalho buscou entender a contribuição dos serviços para o crescimento da produtividade na economia brasileira no período pós Plano Real e lançar luz sobre sua dinâmica, focando a relação entre a estrutura e crescimento, além de explorar sua significativa heterogeneidade.

A relação entre estrutura e crescimento coloca-se como ponto de partida para entender a dinâmica da produtividade, tanto por questões teóricas como por resultados empíricos. O desenvolvimento econômico de um país passa por mudanças da sua estrutura produtiva. Vários autores chamam a atenção para 
um caminho positivo de crescimento, em que as mudanças na estrutura estão associadas com aumentos de produtividade e criação de excedentes maiores, o chamado Bônus Estrutural do crescimento (por exemplo, Timmer \& de Vries 2009) e (para a indústria brasileira, Rocha 2007).

Os resultados encontrados permitem ressaltar que o setor de serviços ao contrário do senso comum é um setor com alta produtividade. Não só o patamar de produtividade do setor é alto, como também a evolução da produtividade desse setor foi positiva no período de 2002 a 2009. O mesmo não foi observado na indústria a qual apresentou queda na produtividade nos períodos estudados de 1996 a 2002 e de 2002 a 2009.

Na literatura internacional, os serviços já foram associados a um desempenho histórico negativo da indústria. Por ser um setor que se caracteriza por ser intensivo em mão de obra e menos expostos à inovação produtiva (em parte), a ampliação da participação dos serviços na economia poderia levar a economia para a estagnação devido ao pobre desempenho produtivo, gerando o que foi chamado de doença de custos por Baumol (1967). Contudo os resultados mostraram que não há evidências favoráveis para a existência da doença de custos no Brasil no período de 2002-2009, uma vez que a produtividade dos serviços cresceu mais que indústria, particularmente dos serviços prestados às empresas. Em adição, a dinâmica da parcela dos serviços no consumo intermediário da indústria de transformação não está associada à dinâmica da produtividade da indústria.

Com o uso das informações da PAS para uma análise mais desagregada, verificou-se que as divisões que compõem os serviços são heterogêneas no patamar e na dinâmica da produtividade, além da intensidade tecnológica. Os serviços prestados às empresas tiveram aumento de produtividade no período recente, descartando, mais uma vez, a possibilidade de explicação do desempenho pífio da produtividade da indústria de transformação pela mudança estrutural da economia para os serviços ou pelo aumento da parcela dos serviços nas compras intermediárias da indústria.

Além de sua marcante heterogeneidade, os serviços apresentaram uma dinâmica em parte similar e em parte diferente da indústria. De forma comum aos setores, a dinâmica da produtividade foi determinada em grande parte pelo desempenho intrassetorial. Ambos os setores não apresentaram um bônus estrutural positivo, em que, na média, setores com ganho de produtividade não apresentaram ganho de importância no emprego. Por outro lado, a realocação do emprego nos serviços contribuiu positivamente para o crescimento da produtividade, enquanto que na indústria essa realocação (alterações estruturais) teve impacto negativo na dinâmica da produtividade industrial.

Encerrando estes comentários finais, este estudo aponta para a importância de aprofundar o conhecimento sobre o setor de serviços, dentro de sua marcante heterogeneidade, buscando entender as diferenças nas trajetórias de produtividade entre indústria e serviços. Direções envolvem o uso de microdados e avaliação de fatores determinantes da produtividade como competição, inovação e qualificação de mão de obra, cada um exigindo uma análise cuidadosa, muito além do escopo deste trabalho. 


\section{Agradecimentos}

Os autores agradecem ao Banco Nacional de Desenvolvimento Econômico e Social (BNDES) pelo suporte financeiro por meio do Fundo de Estruturação de Projetos (FEP). Por meio desse fundo o BNDES financia, na modalidade não-reembolsável, a execução de pesquisas científicas, sempre consoante ao seu objetivo de fomento a projetos de pesquisa voltados para a ampliação do conhecimento científico sobre o processo de desenvolvimento econômico e social. Os autores também agradecem aos pareceristas pelos comentários e pelas sugestões. Os erros e omissões são de responsabilidade dos autores.

\section{Referências Bibliográficas}

Barbosa Filho, F. H., Pessôa, S. A. \& Veloso, F. A. (2010), 'Evolução da produtividade total dos fatores na economia brasileira com ênfase no capital humano - 1992-2007', Revista Brasileira de Economia 64(2), 91-113.

Baumol, W. J. (1967), 'Macroeconomics of unbalanced growth: the anatomy of urban crisis', The American Economic Review 57(3), 415-426.

Baumol, W. J., Blackman, S. A. B. \& Wolff, E. N. (1985), 'Unbalanced growth revisited: asymptotic stagnancy and new evidence', The American Economic Review 75(4), 806-817.

Bonelli, R. \& Fonseca, R. (1998), 'Ganhos de produtividade e de eficiência: novos resultados para a economia brasileira', Pesquisa e Planejamento Econômico 28(2), 273-314.

Busso, M., Madrigal, L. \& Pages, C. (2013), 'Productivity and research missallocation in latin american', The B.E. Journal of Macroeconomics 13(1), 903932.

De La Torre, A., Yeyati, E. L. \& Pienknagura, S. (2013), 'Latin america and the caribbean as tailwinds recede', Search of Higher Growth.

Feijó, C. A. \& Carvalho, P. G. M. (1999), 'O debate sobre a produtividade industrial e as estatísticas oficiais', Economia Aplicada 3(4), 631-646.

Ferreira, P. C. \& Rossi, J. L. (2003), 'New evidence from Brazil on trade liberalization and productivity growth', International Economic Review 44(4), 13831405.

Gomes, V., Pessôa, S. \& Veloso, F. (2003), 'Evolução da produtividade total dos fatores na economia brasileira: uma análise comparativa', Pesquisa e Planejamento Econômico 33(3), 389-434.

Kon, A. \& Kume, H. (2004), Economia de serviços: teoria e evolução no Brasil, Elsevier, Campos.

Melo, H. P., Rocha, F., Ferraz, G., Di Sabbato, A. \& Dweck, R. (1998), 'O setor serviços no Brasil: uma visão global — 1985/95'.

Oliveira, C. C. (2011), 'Os serviços importam: análise comparativa da evolução setorial da produtividade do trabalho no Brasil, nos EUA e na EU-15 (1980-2007): uma aplicação do modelo Shift share', XXXIX Encontro Nacional de Economia, Foz do Iguaçú, Paraná. 
Olley, G. S. \& Pakes, A. (1996), 'The dynamics of productivity in the telecommunications equipment industry', Econometrica 64(6), 1263-1297.

Pereira, M. Z., Bastos, S. Q. A. \& Perobelli, F. S. (2013), 'Análise sistêmica do setor de serviços no Brasil para o ano de 2005', Pesquisa e Planejamento Econômico 43(1), 161-201.

Pinheiro, A. C. (2012), 'Mudanças na economia brasileira', Valor econômico.

Ribeiro, E. P. (2005), 'Produtividade e emprego na indústria do rs, 19962000: especialização ou desempenhos setorial?', Indicadores Econômicos FEE 33(2), 161-174.

Rocha, F. (1999), 'Composição do crescimento dos serviços na economia brasileira: uma análise da matriz insumo-produto (1985-1992)', Journal of Econometrics 61(1), 5-21.

Rocha, F. (2007), 'Produtividade do trabalho e mudança estrutural nas indústrias brasileiras extrativa e de transformação, 1970-2001', Revista de Economia Política 27(2), 221-241.

Rodrik, D. (2011), 'O imperativo manufatureiro', Valor econômico.

Rodrik, D. (2014), 'Are services the new manufactures?', Valor econômico.

Salm, C., Saboia, J. \& Carvalho, P. G. M. (1997), 'Produtividade na indústria brasileira: questões metodológicas e novas evidências empíricas', Pesquisa e Planejamento Econômico 22(2), 377-396.

Schor, A. (2006), 'Efeitos da redução tarifária da década de 1990 sobre a distribuição intra-setorial da produção o e da produtividade na indústria brasileira', Pesquisa e Planejamento Econômico 36(1), 73-107.

Schreyer, P. \& Pilat, D. (2001), 'Measuring productivity', OECD Economic Studies 33(2), 127-170.

Silva, A. M. (2006), Dinâmica da produtividade do setor de serviços no Brasil: uma abordagem microeconômica, in J. A. Negri \& L. C. Kubota, eds, 'Estrutura e Dinâmica do Setor de Serviços no Brasil', Vol. 1, IPEA.

Timmer, M. P. \& de Vries, G. J. (2009), 'Structural change and growth accelerations in Asia and Latin America: a new sectoral data set', Cliometrica 3(2), 165-190.

Van Ark, B., Inklaar, R. \& McGuckin, R. H. (2003), 'Ict and productivity in europe and the united states where do the differences come from?', CESifo Economic Studies 49(3), 295-318. 


\section{Apêndice A Compatibilização de subsetores na PAS}

Para análises entre 2002 e 2009 há o desafio de superarmos a mudança de classificação setorial em 2007 da CNAE 1.0 e CNAE 2.0. Inicialmente, baseado no CONCLA, fazemos uma relação de-para dos setores, nas diferentes classificações, baseado na melhor compatibilização possível. Há setores da CNAE 1.0 que se desdobram em dois (ou mais) na CNAE 2.0 e vice-versa. Após a compatibilização de setores, é necessário criar as séries de valores padronizadas.

Fazemos o cálculo da compatibilização setorial das séries, devido à mudança de classificação entre CNAE 1.0 e 2.0 em três passos.

1. Agrupamos os setores CNAE 2.0 em seus respectivos grupos CNAE 1.0, mesmo que de forma imperfeita (dois para um ou um para dois setores).

2. Utilizamos a presença do ano de 2007 mensurado nas duas classificações para criar um índice da variável (produção ou emprego ou produtividade), baseado no crescimento anual. Note que o crescimento é calculado dentro de cada classificação e assim não é influenciado pela compatibilização de setores.

3. A partir de uma base de emprego, produção ou produtividade, criamos uma série de valores utilizando o índice.

Abaixo temos um exemplo hipotético:

Tabela A.1: Séries em cada classificação setorial

\begin{tabular}{lcccc}
\hline Variável & \multicolumn{2}{c}{ CNAE1.0 } & \multicolumn{2}{c}{ CNAE2.0 } \\
\hline & 2006 & 2007 & 2008 & 2009 \\
\hline Série & 23,6 & 31,7 & 30,8 & 35,5 \\
Crescimento & & $34,32 \%$ & & $15,26 \%$ \\
\hline
\end{tabular}

Tabela A.2: Séries em cada classificação setorial

\begin{tabular}{llll}
\hline & \multicolumn{1}{c}{2006} & \multicolumn{1}{c}{2007} & \multicolumn{1}{c}{2008} \\
\hline Série Base 2006 (CNAE 1,0) & 23,6 & 31,7 & 36,54 \\
Série Base 2008 (CNAE 2,0) & 22,93 & 30,8 & 35,5 \\
Cresc, Base 2006 & & $34,32 \%$ & $15,26 \%$ \\
Cresc, Base 2008 & & $34,32 \%$ & $15,26 \%$ \\
\hline
\end{tabular}

O valor de 36,54 da Série Base 2006 (CNAE 1.0) é obtido aplicando o crescimento de 15,26\% entre 2007 e 2008 (na CNAE 2.0) no valor de 2007 na CNAE $1.0(31,7)$. Já o valor de 22,93 para o ano de 2006 na série base 2008 (CANE 2.0) é obtido aplicando o crescimento de $34,32 \%$ no valor de 30,8 de 2007 (base CNAE 2.0).

A grande vantagem do método é garantir que a dinâmica da série não seja influenciada pela agregação, principalmente entre os anos de mudança de classificação (2007), como vemos nas duas últimas linhas da Tabela A.2. 


\section{Apêndice B Agregação em grandes setores}

Empregamos uma agregação setorial mais próxima das Contas Regionais, em que a indústria extrativa mineral foi alocada no setor Agropecuária e Recursos Naturais, ficando a Indústria como Indústria de Transformação apenas. Essa classificação setorial não altera as tendências verificadas nas Tabelas 1 e 2 .

Para deixar completa a análise apresentamos abaixo as Tabelas B.1 e B.2 em que a Indústria inclui tanto a indústria de transformação como a indústria extrativa mineral. Vemos que as tendências da indústria não dependem da agregação realizada.

Tabela B.1: Crescimento do PIB

\begin{tabular}{lccccc}
\hline Ano & Agric & Ind Extr., Transform e Ccivil & Com & Svc & Total \\
\hline $2002-2009$ & $22.60 \%$ & $18.60 \%$ & $33.60 \%$ & $28.60 \%$ & $26.00 \%$ \\
$1996-2002$ & $29.50 \%$ & $8.00 \%$ & $4.10 \%$ & $16.70 \%$ & $13.20 \%$ \\
\hline
\end{tabular}

Fonte: cálculos dos autores baseados nas Contas Nacionais IBGE (TRU).

Valores a preços constantes de 2008, calculados por duplo deflacionamento de produção e consumo intermediário, baseado em deflatores de preços construídos das informações a preços correntes e preços do ano anterior.

Tabela B.2: Crescimento do PIB

\begin{tabular}{lcccrr}
\hline Ano & Agric & Ind Extr., Transform e Ccivil & Com & \multicolumn{1}{c}{ Svc } & \multicolumn{1}{c}{ Total } \\
\hline $2002-2009$ & $26,80 \%$ & $-5,30 \%$ & $13,60 \%$ & $4,60 \%$ & $7,70 \%$ \\
$1996-2002$ & $32,10 \%$ & $-2,60 \%$ & $-17,10 \%$ & $-5,10 \%$ & $-1,40 \%$ \\
\hline
\end{tabular}

Fonte: cálculos dos autores baseados nas Contas Nacionais IBGE (TRU). Valores a preços constantes de 2008. Vide Tabela 1.

Produtividade do Trabalho = Valor Adicionado/Emprego. 